\title{
Eco-biology and conservation of potential insectivorous birds in the arable biomes of central Punjab
}

\author{
Muhammad Akhtar ${ }^{1 *}$, Rasheed Ahmad Khan ${ }^{1}$, Muhammad Tahir \\ Saddiqui ${ }^{1}$ and Hammad Ahmad Khan ${ }^{2}$ \\ 1. Department of Forestry and Range Management, University of Agriculture, Faisalabad-Pakistan \\ 2. Department of Zoology and Fisheries, Faculty of Sciences, University of Agriculture, Faisalabad-Pakistan \\ *Corresponding author's email: Akhtar_frw@yahoo.com \\ Citation \\ Muhammad Akhtar, Rasheed Ahmad Khan, Muhammad Tahir Saddiqui and Hammad Ahmad Khan. Eco-biology \\ and conservation of potential insectivorous birds in the arable biomes of central Punjab. Pure and Applied Biology. \\ Vol. 5, Issue 4, pp1254-1259. http://dx.doi.org/10.19045/bspab.2016.50150
}

Received: $17 / 08 / 2016$

Revised: $21 / 10 / 2016$

Accepted: $30 / 10 / 2016$

Online First: 18/11/2016

\section{Abstract}

The present study was conducted to investigate the eco-biology of insect predator avian species and the effects of environmental factors on the eco-biology and bird populations in Punjab, Pakistan. Data on ecology and other aspects of bank myna was collected from three districts of Central Punjab including Faisalabad (an industrial area with large effects of heavy metals by usage of sewage water of industries in irrigation \& pesticides), Sargodha (with medium level of industries \& pesticides use) and Mandi Bahauddin (no industry and low use of pesticide). Specimens were collected to observe gut contents. Gut contents were analyzed to account for the prey and feeding niche. Major insect pests of crops were identified and listed from gut contents. Relative population density of useful birds was assessed and continuously monitored for population trends around the year. Breeding ecology of both predacious birds was studied to evaluate breeding success, mortality rate and to weigh up the effects of pesticides used and pollution. Breeding ecology, population dynamics and gut contents analysis were significantly ( $\mathrm{P}$ $\left.\leq 0.001 ; \mathrm{R}^{2} \geq 0.75\right)$ influenced by the use of pesticides. It was concluded that use of pesticides without studying their toxic effects is detrimental to these predacious birds. Blind sprays should be prohibited and alternatives should be adopted to conserve the predacious birds in order to achieve effective biological control.

Keywords: Predacious birds; Eco-biology; Population dynamics

Introduction

The bank myna (Acridotheres ginginianus) is a member of family Sturnidae, native to South Asia, smaller in size but similar in colour to the common mynah (A. tristis) the major differences are: the presence of a brick red bare skin patch behind the eye in place of yellow; greyer undersides with presence of slight tuft of feathers, bearing a resemblance with the jungle myna $(A$. fuscus). Head is black on the crown and sides and the upper plumage is slaty grey while the underside is lighter grey with pale pink plumage towards the center of the abdomen the birds have black wings with a wing patch at the base of the primaries, and 
the tips of the outer tail feathers are pale pinkish buff. The sexes are indistinguishable in the field. Young birds have a browner head and neck [1]. Bank mynas feed on grains, insects and fruits. They feed on a variety of insects, including some crop pests such as Achaea janata whose caterpillars feed on castor [2]. Clutch size normally ranges from 4-6 eggs and average size of egg measured $30.8 \times 21.99 \mathrm{~mm}$. Incubation period ranges from 17-18 days and fledging period from 22-24 days [3]. Bank mynas build nests in cavities of trees, walls and canal bank and breed from sea-level to 3000 $\mathrm{m}$ in the Himalayas. Nesting material usually consists of twigs, roots, tow and rubbish. Sometime they also use nests of woodpeckers, parakeets, etc. and aggressive behaviour is used to contribute towards its success as an invasive species [4].

Food choice of birds can be assessed by analyzing gut contents. Population structure and gut contents of 32 bird species were analyzed by [5]. Among them 31 species were Passeriformes and one Coraciiform. Whereas 23 were endemic and 9 were migratory in nature. Indian wren warbler, bank myna and jungle babbler, were recorded frequently Rosy Pastor, Jungle Sparrow, Yellow-throated Sparrows were rare; small Green Bee Eater was recorded during maturity stage of cotton with density of $0.8 \mathrm{birds} /$ hectare and potential in insect predation. Indian wren warbler, jungle babbler, common babbler and bank myna, were recorded throughout the year and their combined population was estimated up to $7.1 \mathrm{birds} / \mathrm{ha}$. The total estimated bird density was 14.6 birds per hectare. More than $1 / 3$ $(37 \%)$ of the bird species mostly concentrate on insects for food. Insects belonging to the orders Hymenoptera and Hemiptera formed the major proportion of arthropod based food. Common aphids and thrips dominated the food of the Indian Wren Warbler. Cattle movements disturb insect population in fields. However, [6] investigated ecological linkages of the bird species with livestock. The insects in the pastureland dislodged by the livestock are eaten by cattle egrets, bank mynas and black drongos. Bank mynas and black drongos were estimated to consume insect mass of consuming upto $1 / 6$ of their body weight per day; however, Cattle Egrets and Crested Larks were recorded consuming upto $1 / 3$ of their own body weight per day. The percentage of grasshoppers and beetles in diets of these species was found higher than found in guts of other insectivorous bird species.

Ticks are also found in gut contents. [7] observed crops $(n=7,334)$ contents from 239 species of birds for ticks. They recorded ticks in bank myna, helmeted guinea fowl, crowned plover and lila breasted roller. All these ticks belonged to genera Boophilus, Hyalomma and Rhipicephalus. Gut content of birds' species reported showed diversity of insect species preyed by birds. Some birds prefer certain insects while others reject them. It implies that birds are prey specific to some extent.

Clutch size normally ranged from 4-6 eggs and average size of egg measured $30.8 \times 21.99 \mathrm{~mm}$. Incubation period ranged from 17-18days and fledging period from 22-24 days [8]. Some time they also use nests of woodpeckers, parakeets etc. and aggressive behavior is recorded for success towards invasive species [4]. Cattle Egrets spend their life in colonies. Breeding season varies within Asia. Nesting usually begins with onset of monsoons [8]. Breeding success is related to number of newly hatched birds. [9] evaluated the breeding success of Bubulcus ibis (Ardeidae), Egretta thula, Nycticorax nycticorax, Phimosus infuscatus and Plegadis chihi for two consecutive nesting seasons. Mean clutch size for $B$. ibis was 2.59 and 2.49, respectively. The mean number of nestlings/nest was 1.85 for $B$. ibis. In both 
nesting seasons all the species had major success, laying three eggs and raising two nestlings, except for $B$. ibis. However, breeding success for $B$. ibis ranged from 1.16 in the first period to 0.99 in the second.

\section{Materials and methods}

The present experiment was conducted at three locations of Punjab (Faisalabad, Sargodha and Mandi Bahauddin). Two sites were selected in each district with GPS readings to identify the actual location of selected study site. Faisalabad $30^{\circ} 40^{\prime}$ to $31^{\circ}$ $47^{\prime} \mathrm{N}, 72^{\circ} 42^{\prime}$ to $73^{\circ} 40^{\prime} \mathrm{E}$, Sargodha $31^{\circ}$ $49^{\prime} 60 \mathrm{~N}, 72^{\circ} 37^{\prime} 60 \mathrm{E}$ and Mandi Bahauddin $32^{\circ} 34^{\prime} 60 \mathrm{~N}, 73^{\circ} 30^{\prime}$ 0E. Population surveys of the selected birds from three habitats (six sites) were made to record the distribution of bird species among these sites. Survey was conducted using three method: i) By direct visual analysis, ii) by telescope studies iii) by taking pictures and counting birds. Among these sites, there was an extremely large range of population sizes among bird species, (<1000 mature individuals) and these fluctuated with regard to the nature of habitat extent/ quality. In some places population size was recorded in small number at 2-3 locations/ fragmentation [10]. Population was estimated by transect methods through searching and counting active nests of the cattle egret and bank myna in the aforesaid areas, either on foot, by boat or vehicle. Active nests were identified by seeing the pairs engaged in nest building and/or renovation. Gut content analysis was made to determine the detrimental effects of pesticides and pollution. 10 birds were hunted/shot each time and 24 observations were completed during the study by two weeks sampling $(n=240)$, The birds were killed using an air gun/shot gun (Diana 35 Model BB shots) according to a specific schedule at 10-11 am and 4-5 pm. The crop of each killed bird was extracted in the field, tagged properly, brought to the lab and was preserved in $10 \%$ alcohol for final analyses (Pedigo, 1996), the morphological measurements made from the hunted birds. At the end of each trip the crops were cut opened; contents were weighed and taken out in a shallow pans or petri-dishes. Needles were used to spread the items for identification. Fragments of the insects were isolated to identify the species and the total number of useful and harmful arthropods consumed. Field lens (10X) and microscope was also used occasionally to confirm the identification of insects. Observations were recorded continuously throughout the research period according to the previously described schedule [1, 11]. After collection, data were analyzed statistically using Analysis of Variance or Chi square tests. The statistical packages Statistix version 8.1 and SPSS version 16.0 were used for all analysis.

\section{Results and discussion \\ Morpho-taxonomical features}

During present study10 birds of bank myna were killed and 15 live birds were visualized by telescope in each survey to study the morphological features (Table 1) from each study site at the end of sampling season (October and March), and following observations were recorded: it was difficult to differentiate between sexes in the field and juveniles were with a browner head and neck; head of each birds was black on the crown and sides, whereas upper plumage was slaty grey and underside was lighter grey with pale pink plumage towards the center of the abdomen. Wings were black, having a wing patch at the base of the primaries and the tips of the outer tail feathers were pale pinkish buff. However, naked skin behind the eye was brick red, legs were yellow, and iris was deep red. The study was confirmed by other scientist as the results were in the same pattern [12]. 
Table 1. Physical characteristics of bank myna

\begin{tabular}{|l|l|l|l|}
\hline Character & Measurement $(\mathbf{c m})$ & Character & Measurement(cm) \\
\hline Body length & $10-15$ & Wing span & $40-50$ \\
\hline Wing length & $20-25$ & Tail length & $8-10$ \\
\hline Bill length & $2-2.5$ & Body weight & $75-300 \mathrm{gm}$ \\
\hline
\end{tabular}

\section{Clutch size}

Clutch size of bank mynah on average in non-treated areas, was the largest at Mandi Bahauddin $(4.00 \pm 0.87)$ with average egg size of (1.08 x 0.86), followed by Sargodha $(3.83 \pm 0.76 ; 1.08 \times 0.86)$ and then
Faisalabad ( $3.17 \pm 0.58 ; 1.07$ x 0.86). Similar trend was found in treated areas. However, the largest clutch size was recorded from Mandi Bahauddin (Table 2). There clutch study was in the pattern of [13].

Table 2. Clutch size and egg measurements of bank myna observed at three sites

\begin{tabular}{|l|l|l|l|l|l|}
\hline \multirow{2}{*}{ Location } & $\begin{array}{l}\text { No. of nests } \\
\text { observed }\end{array}$ & $\begin{array}{l}\text { Clutch size } \\
\text { (Mean } \pm \text { SD) }\end{array}$ & $\begin{array}{l}\text { Avg. Egg } \\
\text { Measurement } \\
\text { (inch) }\end{array}$ & $\begin{array}{l}\text { Clutch size } \\
\text { (Mean } \pm \text { SD) }\end{array}$ & $\begin{array}{l}\text { Avg. Egg } \\
\text { Measurement } \\
\text { (inch) }\end{array}$ \\
\cline { 3 - 6 } & \multicolumn{2}{|l|}{ Non-treated } & Treated \\
\hline Faisalabad & 15 & $3.17 \pm 0.58^{\mathrm{A}}$ & $1.07 \times 0.86^{\mathrm{A}}$ & $2.33 \pm 0.29^{\mathrm{B}}$ & $1.03 \times 0.83^{\mathrm{B}}$ \\
\hline Sargodha & 15 & $3.83 \pm 0.76^{\mathrm{A}}$ & $1.08 \times 0.86^{\mathrm{A}}$ & $2.83 \pm 0.76^{\mathrm{B}}$ & $1.04 \times 0.84^{\mathrm{B}}$ \\
\hline Mandi Bahauddin & 15 & $4.00 \pm 0.87^{\mathrm{A}}$ & $1.08 \times 0.86^{\mathrm{A}}$ & $2.67 \pm 0.58^{\mathrm{B}}$ & $1.07 \times 0.85^{\mathrm{B}}$ \\
\hline
\end{tabular}

\section{Gut content analysis}

Gut content analyses are given in Table 3. The largest material was found in the gut of birds in non-treated areas of Mandi Bahauddin (5.89 \pm 0.40 grams) which ranged from $4.2-6.25 \mathrm{~g}$. The smallest contents were observed in the crops of birds from treated areas of Faisalabad (5.14 \pm 0.95 grams) that ranged from 3.2-6.2 g . Insect material was recorded the largest from non-treated areas of Mandi Bahauddin $(3.76 \pm 0.51$ grams $)$ and the smallest from treated areas of Faisalabad ( $2.71 \pm 0.55$ grams). Weight of fed material other than insects was recorded the largest from treated areas of Faisalabad $(2.44 \pm 0.73$ grams) and the smallest from non-treated areas of Mandi Bahauddin $(2.13 \pm 0.47$ grams). However, average number of insects fed was the highest among non-treated areas of Mandi
Bahauddin (63.78 \pm 7.46 grams) and lowest among non-treated areas of Faisalabad $(51.76 \pm 7.63$ grams). Percentage $(\%)$ of harmful insects fed was different in different areas. It was observed the largest in nontreated areas of Mandi Bahauddin (85.42\%) and the smallest in treated areas of Faisalabad (41.67\%). Percentage of harmful insects fed by bank myna was high in treated areas of Faisalabad (46.25\%) as compared to non-treated areas $(41.67 \%)$ ). It was due to frequent availability of insect pests feeding on garbage and decayed fruits, and daily house wastage near the city areas. Observed variations in gut contents might be due to seasonal variation in frequency of pest. The major portion of food of the common mana is insects [5]. The study was also confirmed on other bird species [14]. 
Table 3. Mean weight of gut contents of bank myna from three sites

\begin{tabular}{|l|l|l|l|l|l|l|}
\hline \multirow{2}{*}{ Location } & Treatment & $\begin{array}{c}\text { AGCW } \\
(\text { Mean } \pm \text { SD) }\end{array}$ & $\begin{array}{c}\text { AIW g } \\
(\text { Mean } \pm \text { SD) }\end{array}$ & $\begin{array}{c}\text { ANIW g } \\
(\text { Mean } \pm \text { SD) }\end{array}$ & $\begin{array}{c}\text { ANI } \\
(\text { Mean } \pm \text { SD })\end{array}$ & \% HIF \\
\hline Faisalabad & Non-treated & $5.14 \pm 0.95^{\mathrm{A}}$ & $2.71 \pm 0.55^{\mathrm{B}}$ & $2.43 \pm 0.62^{\mathrm{A}}$ & $51.76 \pm 7.63^{\mathrm{B}}$ & $41.67^{\mathrm{B}}$ \\
\cline { 2 - 7 } & Treated & $5.40 \pm 0.88^{\mathrm{A}}$ & $2.96 \pm 0.56^{\mathrm{A}}$ & $2.44 \pm 0.73^{\mathrm{A}}$ & $55.42 \pm 9.99^{\mathrm{A}}$ & $46.25^{\mathrm{A}}$ \\
\hline \multirow{2}{*}{ Sargodha } & Non-treated & $5.67 \pm 0.64^{\mathrm{A}}$ & $3.34 \pm 0.64^{\mathrm{A}}$ & $2.33 \pm 0.61^{\mathrm{B}}$ & $58.96 \pm 9.97^{\mathrm{A}}$ & $59.67^{\mathrm{A}}$ \\
\cline { 2 - 7 } & Treated & $5.18 \pm 0.85^{\mathrm{B}}$ & $2.83 \pm 0.53^{\mathrm{B}}$ & $2.35 \pm 0.54^{\mathrm{A}}$ & $54.83 \pm 6.33^{\mathrm{B}}$ & $41.75^{\mathrm{B}}$ \\
\hline $\begin{array}{l}\text { Mandi } \\
\text { Bahauddin }\end{array}$ & Non-treated & $5.89 \pm 0.40^{\mathrm{A}}$ & $3.76 \pm 0.51^{\mathrm{A}}$ & $2.13 \pm 0.47^{\mathrm{B}}$ & $63.78 \pm 7.46^{\mathrm{A}}$ & $85.42^{\mathrm{A}}$ \\
\cline { 2 - 7 } & Treated & $5.37 \pm 0.56^{\mathrm{B}}$ & $3.03 \pm 0.44^{\mathrm{B}}$ & $2.34 \pm 0.52^{\mathrm{A}}$ & $56.61 \pm 7.52^{\mathrm{B}}$ & $76.96^{\mathrm{B}}$ \\
\hline
\end{tabular}

AGCW= Avg. Gut content weight (fresh); AIW= Avg. Weight if insect material; ANIW= Avg. Weight of other material other than insects; ANI= Avg. No. of insect fed; HIF= harmful insects fed

\section{Comparison of feeding flocks of bank myna}

The differences between locations were significant $(\mathrm{P}<0.05)$ for feeding flock sizes (Table 4). Data on sampling feeding flocks of bank myna from three districts is presented in Table 5.2.6. Average number within feeding flocks of bank myna $( \pm \mathrm{SD})$ was $695 \pm 60.6$ birds. The largest flocks were recorded from Mandi Bahauddin and
Sargodha districts $(45 \pm 4.2$ birds $)$ while the smallest population was recorded from Mandi Bahauddin district ( $25 \pm 4.2$ birds). However, equal population from Mandi Bahauddin and Sargodha districts was owing to that in Mandi Bahauddin district, control areas were adjoining to village residences (limiting the population size) and pesticides were equally affecting both the populations [15].

Table 4. Average number of Feeding Flocks of bank myna in three habitats

\begin{tabular}{|l|l|l|l|}
\hline \multirow{1}{*}{\multicolumn{1}{c|}{ Habitat }} & \multicolumn{1}{|c|}{ Faisalabad } & \multicolumn{1}{c|}{ Sargodha } & \multicolumn{1}{c|}{ Mandi Bahauddin } \\
\cline { 2 - 4 } & \multicolumn{1}{c|}{ Mean \pm SD } & \multicolumn{1}{c|}{ Mean \pm SD } & \multicolumn{1}{c|}{ Mean \pm SD } \\
\hline Crop Land & $20.0 \pm 0.00$ & $27.5 \pm 3.54$ & $37.5 \pm 3.54$ \\
\hline Irrigated Fields & $86.5 \pm 12.02$ & $114.0 \pm 7.07$ & $119.0 \pm 19.80$ \\
\hline Marsh Areas & $93.0 \pm 14.14$ & $101.5 \pm 16.26$ & $117.5 \pm 6.36$ \\
\hline Canal side & $89.0 \pm 26.87$ & $107.5 \pm 10.61$ & $160.0 \pm 0.00$ \\
\hline Ploughed Fields & $161.0 \pm 9.90$ & $166.5 \pm 16.26$ & $145.0 \pm 15.56$ \\
\hline Ponds & $143.5 \pm 21.92$ & $214.0 \pm 18.38$ & $256.0 \pm 16.97$ \\
\hline Newly Harvested Fields & $89.5 \pm 30.41$ & $109.5 \pm 20.51$ & $119.5 \pm 34.65$ \\
\hline
\end{tabular}

\section{Conclusion}

The results demonstrated that these birds are gregarious feeders, live together and breed in flocks, feed on crop insect pests and play a very important role in the management of insect population.

\section{Authors' contributions}

Conceived and designed the experiments: $\mathrm{M}$ Akhtar, Performed the experiments: M Akhtar, Analyzed the data: RA Khan Contributed reagents/ materials/ analysis tools: MT Saddiqui, Wrote the paper: HA Khan.

\section{Acknowledgement}

The authors are thankful to Higher Education Commission, Islamabad for financial support for the project leading to Ph.D. Thanks to the Punjab Government for supporting me. Special thanks to Dr. Irfan Ashraf, Department of Forestry, Range \& Wildlife Management, The Islamia 
University of Bahawalpur, Pakistan for cooperation regarding my thesis write up.

\section{References}

1. Abdullah M (2007). Eco-biology and conservation activity of cattle egret (Bubulcus ibis) in croplands. M.Sc. (Hons.) thesis, Deptt. Forestry, Univ. Agri. Faisalabad, Pakistan.

2. Rasmussen PC \& Anderton JC (2005). Birds of South Asia. The Ripley Guide. Volume 2. Smithsonian institution and Lynx Edicions Pp 584.

3. Pande S, Tambe S, Francis CF \& Sant N (2003). Birds of Western Ghats, Kokan and Malabar (including Birds of Goa), Oxford University Press, Mumbai, Pp ixii+377.

4. Hussain I \& Afzal M (2005). Insectivorous birds and their significance in a cotton wheat based agro ecosystem of Punjab. Pakistan J Zool 37: 133-134.

5. Irshad S \& Mirza ZB (2009). Ecological and socioeconomic linkagesof birds of ravi Riverine Habitats. Pakistan J Zool 43(1): 113-122.

6. Petney TN \& Kok OB (2004). Birds as predators of ticks (Ixodoidea) in South Africa. Experimental and Applied Acarology 17: 393-403.

7. Ali S \& Ripley SD (2001). Handbook of the birds of India and Pakistan (Vol.9). Oxford University Press, New Delhi.

8. Hilaluddin, Kaul R, Hussain MS, Imam E, Shah JN, Abbasi F \& Shawl TA (2005). Status and distribution of breeding cattle egret and little egret in Amroha using density method. Current Sci 88: 350-369.
9. Petry MV \& Fonseca VSDS (2005). Breeding success of the colonist species (Bubulcus ibis L.) and four native species. Acta Zoologica 86: 217-221.

10. Grimmett R, Roberts $T$ \& Inskipp $T$ (2008). Birds of Pakistan. Christopher Helm, London. Pp. 256.

11. Azeem \& Waqar M (2010). Eco-biology and insectivorous activity of bank myna (Acridotheres ginginianus). M.Sc. (Hons.) thesis, Deptt. Forestry, Univ. Agri. Faisalabad, Pakistan.

12. Ujan HM, Birmani NA \& Shaikh AM (2014). Echinochasmus mazharuddini n.sp. (Digenea: Echinostomatidae) from the bank myna Acridotheres ginginianus L. (Passeriformes: Sturnidae) in Sindh province, Pakistan. $J$ of Entom and Zool Studies 2: 226-232.

13. Jadhav A \& Parasharya BM (2003). Some observations on the nesting behaviour and food of the spotted owlet athene brama. Zoos print journal 18: 1163-1165.

14. Hussain T, Ashraf I, Ahmed I, Ruby T, Rafay M, Abdullah M, Siddiqa N, Nawaz S \& Akhtar S (2016). Comparison of Diet Analysis of Eurasian Sparrowhawk, Accipiter nisus and Black Kite, Milvus migrans (Accipitridae: Accipitriformes) from Southern Punjab, Pakistan. Pakistan J Zool 48(3): 789-794.

15. Durranee, Hasnain JSA \& Ahmad E (2008). Observations on the Birds of Sandspit/ Hawkesbay Coastal Wetland Complex, Karachi Coast. Pakistan J Zool 40: 229-237. 